\title{
CD40, autophagy and Toxoplasma gondii
}

\author{
Carlos S Subauste \\ Department of Ophthalmology and Visual Sciences, Division of Infectious Diseases and HIV Medicine, Department of Medicine and \\ Department of Pathology, Case Western Reserve University School of Medicine, OH 44106 Cleveland, USA
}

Toxoplasma gondii represents a pathogen that survives within host cells by preventing the endosomal-lysosomal compartments from fusing with the parasitophorous vacuoles. The dogma had been that the non-fusogenic nature of these vacuoles is irreversible. Recent studies revealed that this dogma is not correct. Cell-mediated immunity through CD40 re-routes the parasitophorous vacuoles to the lysosomal compartment by a process called autophagy. Autophagosome formation around the parasitophorous vacuole results in killing of the T. gondii. CD40-induced autophagy likely contributes to resistance against $\mathrm{T}$. gondii particularly in neural tissue.

Key words: macrophage - lysosome - endosome - IFN- $\gamma$ - nitric oxide

Toxoplasma gondii is an excellent example of a pathogen of clinical importance that avoids eradication by the host. Indeed, T. gondii causes a chronic infection in humans despite the onset of an immune response. This infection can reactivate under conditions that impair cellmediated immunity leading to disease (toxoplasmosis). One of the mechanisms utilized by the parasite to avoid eradication relies on its residence within a compartment - the parasitophorous vacuole - that avoids fusion with late endosomes-lysosomes. This is a key feature of the biology of the parasite because $T$. gondii cannot survive within the lysosomal compartment.

The parasitophorous vacuole is formed during the process of active invasion of host cells. The membrane of the vacuole is extensively modified because $T$. gondii excludes many host cell proteins and inserts proteins of parasite origin (Hakansson et al. 2001, Joiner \& Roos 2002). Host endocytic structures are recruited to the parasitophorous vacuole and delivered intact into the vacuolar space (Coppens et al. 2006). However, no release of endosomal contents into the vacuole takes place. The dogma had been that once the parasitophorous vacuole is formed, its non-fusogenic nature could not be changed (Joiner et al. 1990, Mordue \& Sibley 1997). Thus, a critical question in the interaction between $T$. gondii and the immune system has been whether there is a way to change the non-fusogenic nature of the parasitophorous vacuole. This question is not only relevant to $T$. gondii but also to the large number of pathogens that survive by avoiding phago-lysosomal fusion. We recently demonstrated that this is achieved through CD40 stimulation (Andrade et al. 2006, Subauste et al. 2007a).

Financial support: National Institutes of Health, American Heart Association (Ohio Valley Affiliate), Juvenile Diabetes Research Foundation International, Research to Prevent Blindness Foundation, Ohio Lions Eye Research Foundation

Corresponding author: carlos.subauste@case.edu

Received 10 October 2008

Accepted 3 December 2008

\section{CD40 and the immune response against $T$. gondii}

IFN- $\gamma$ is essential for protection against $T$. gondii in mice. IFN- $\gamma$-deficient mice die of fulminant infection even when challenged with an avirulent strain of the parasite (Suzuki et al. 1988, 1989, Gazzinelli et al. 1991) and this cytokine is required for resistance against toxoplasmic encephalitis and ocular toxoplasmosis (Suzuki et al. et al. 1989, Gazzinelli et al. 1993, 1994). TNF- $\alpha$, NOS2 and the production of nitric oxide are other components of the immune response critical to control the parasite in the brain and eye (Gazzinelli et al. 1993, 1994, Hayashi et al. 1996a, b, Scharton-Kersten et al. 1997, DeckertSchluter et al. 1998, Yap et al. 1998, Roberts et al. 2000). These findings are in agreement with the synergistic role of IFN- $\gamma$ and TNF- $\alpha$ for induction of NOS2.

Although IFN- $\gamma /$ TNF- $\alpha$-NOS2 are key for resistance against $T$. gondii in neural tissue, it is likely that there are other components of cellular immunity that are required for control of the parasite in these sites. This possibility is particularly relevant to humans because of their restricted expression of NOS2 and because patients with a mutation in IFN- $\gamma \mathrm{R} 1$ that prevents recruitment of STAT1 do not develop disease after T. gondii infection while STAT ${ }^{-/}$mice die acutely after challenge with the parasite (Janssen et al. 2002, Gavrielescu et al. 2004, Lieberman et al. 2004).

CD40 is a member of the TNF receptor superfamily expressed on antigen presenting cells and various nonhematopoietic cells (van Kooten \& Banchereau 2000). Its counter receptor, CD154 (CD40 ligand) is expressed primarily on activated $\mathrm{CD} 4^{+} \mathrm{T}$ cells (van Kooten \& Banchereau 2000). The interaction between CD40 and CD154 regulates several aspects of cellular and humoral immunity (van Kooten \& Banchereau 2000). Many studies reported that this pathway mediates resistance against $T$. gondii in humans and mice. Patients with Xlinked Hyper IgM syndrome (X-HIGM, a congenital immunodeficiency caused by lack of functional CD154) are susceptible to toxoplasmosis (Leiva et al. 1998, Subauste et al. 1999). The CD40 - CD154 pathway restricts the growth of T. gondii in peripheral tissues during the acute phase of infection (Subauste \& Wessendarp 2006). How- 
ever, the role of this pathway is particularly important for control of the parasite in the brain. CD154 $4^{-/}$mice are susceptible to toxoplasmic encephalitis (Reichmann 2000).

The CD40 - CD154 pathway promotes a type $1 \mathrm{cy}-$ tokine response against $T$. gondii in humans (Subauste 1999, Subauste \& Wessendarp 2000) and mice (Subauste $\&$ Wessendarp, unpublished observations). However, studies in mouse models of $T$. gondii infection indicate that this pathway also activates mechanisms of host resistance that act independently of IFN- $\gamma$ (Reichmann 2000). CD154 ${ }^{-/}$mice develop toxoplasmic encephalitis despite upregulation of IFN- $\gamma$ in the brain that is similar to that of infected wild-type mice (Reichmann et al. 2000). These findings raise the possibility that the CD40 - CD154 pathway triggers an alternate pathway to promote resistance to $T$. gondii in neural tissue.

CD40 transforms the parasitophorous vacuole into a compartment that fuses with late endosomeslysosomes

Macrophages and microglia are effectors of resistance against $T$. gondii (Gazzinelli et al. 1993, Robben et al. 2005, Deckert et al. 2006). Macrophages and T cells infiltrate the brain and the retina in cerebral and ocular toxoplasmosis (Schluter et al. 1991, Gazzinelli et al. 1994). Therefore, $\mathrm{CD}_{154^{+}}$T. gondii-reactive activated $\mathrm{CD}^{+} \mathrm{T}$ cells likely trigger $\mathrm{CD} 40$ signaling in macrophages and resident microglia. CD40 stimulation of macrophages allows them to acquire toxoplasmacidal activity (Andrade et al. 2003, 2005a, b, 2006). This effect is not only mediated by recombinant CD154 or an agonistic anti-CD40 mAb but also by CD154 expressed on the membrane of activated $\mathrm{CD} 4^{+} \mathrm{T}$ cells (Andrade et al. 2005a). Killing of $T$. gondii tachyzoites induced by CD40 does not require IFN- $\gamma$, or effector molecules downstream of this cytokine: NOS2 and Immune Related GTPases (IRG) (Andrade et al. 2003, 2005a, Subauste \& Wessendarp 2006). In addition, killing of the parasite is not mediated by the oxidative pathway or starvation for tryptophan (Andrade et al. 2005a).

CD40 causes fusion of parasite-containing vacuoles with late endosomes-lysosomes (Andrade et al. 2006, Subauste et al. 2007a). A critical question was whether parasitophorous vacuoles, which by definition have been considered non-fusogeneic, fused with late endosomeslysosomes. The formation of parasitophorous vacuoles involves secretion of contents of parasite organelles located in the apex of the organism (Archbarou et al. 1991, Cesbron-Delauw 1994, Carruthers \& Sibley 1997). The use of transgenic parasites that express a fluorescent protein targeted to the dense granules allowed to demonstrate that vacuoles where contents of the dense granules are secreted into the vacuolar lumen fuse with late endosomes-lysosomes (Andrade et al. 2006). Moreover, preformed parasitophorous vacuoles still fuse with late endosomes-lysosomes even if CD40 is engaged $18 \mathrm{~h}$ after infection (Andrade et al. 2006). These studies demonstrated that the immune system through CD40 alters a fundamental aspect of the biology of T. gondii: avoidance of lysosomal degradation.
CD40 induces killing of $T$. gondii through vacuolelysosome fusion because pharmacologic inhibition and genetic manipulation of molecules key for vesicular trafficking and lysosomal degradation [lysosomal enzymes, vacuolar ATPase, class III phosphatidylinositol 3-kinase (PI3K) or hVps34, Rab7] abrogate killing of $T$. gondii induced by CD40 (Andrade et al. 2006). These studies uncovered a new paradigm where interaction between CD154 on T cells and CD40 expressed on macrophages leads to killing of an intracellular pathogen via the induction of vacuole-lysosomal fusion (Andrade et al. 2006, Subauste et al. 2007a). Vacuole-lysosome fusion induced by CD40 likely contributes to host protection because CD40 stimulation in vivo induces macrophage toxoplasmacidal activity and reduces the parasite load (Subauste \& Wessendarp 2006).

\section{CD40 induces vacuole - lysosomal fusion and toxo- plasmacidal activity through autophagy}

Studies of expression of endosomal-lysosomal markers revealed that while late endosomal-lysosomal markers (Mannose 6-phosphate receptor, Rab7, LAMP-1, LAMP-2, CD63, cathepsin D) are recruited to the parasitophorous vacuole, this is not preceded by recruitment of the early endosomal markers Rab5, EEA1 (Andrade et al. 2006). These findings suggested that CD40 re-routes the parasitophorous vacuole to the endosomal-lysosomal compartment using a mechanism that differs from the classical pathway of phago-lysosomal fusion.

Autophagy is a process that directs cytoplasmic material and organelles to the lysosomes (Mizushima et al. 2002, Levine \& Klionsky 2004). This is a ubiquitous and highly conserved process present in eukaryotic cells. In response to starvation and other forms of stress, an isolation membrane is produced by polymerization of autophagy proteins (Atg) that belong to two ubiquitinlike conjugation systems: Atg8 (LC3) and Atg12-Atg5 (Ohsumi 2001). This process is driven by the complex of the Atg6 (Beclin 1) with class III PI3K (hVps34) (Kihara et al. 2001). The isolation membrane engulfs portions of cytosol and organelles leading to the formation of autophagosomes (Dunn 1994, Mizushima et al. 2002, Levine \& Mizushima 2004). Fusion between autophagosomes and endosomes-lysosomes culminates in the formation of autolysosomes and degradation of their contents (Dunn 1994). Thus, autophagy represents an alternate route to the lysosomal compartment. Autophagy is a homeostatic process that allows cells to adapt to environmental changes and that enables cells to degrade damaged or surplus organelles. Recent studies revealed that autophagy has a much wider role that includes regulation of aging and development, protection against cancer and neurodegeneration (Ravikumar et al. 2002, Melendez et al. 2003, Qu et al. 2003).

Autophagy has recently been identified as an innate mechanism that leads to degradation of pathogens such as Streptococcus pyogenes, metabolically arrested Listeria monocytogenes, Salmonella enterica (Rich et al. 2003, Nakagawa et al. 2004, Birmingham et al. 2006). Shigella flexneri and Herpes simplex virus 1 (HSV-1) that lack the virulence factors IscB and ICP34.5, respec- 
tively, are also targeted by autophagosomes (Talloczy et al. 2002, Ogawa et al. 2004). Autophagy induced by starvation or rapamycin also kills Mycobacteria (Gutierrez et al. 2004, Singh et al. 2006). A critical question was to determine whether adaptive immunity activates autophagy to kill pathogens. IFN- $\gamma$ induces autophagosomes that target Mycobacterium tuberculosis (Gutierrez et al. 2004, Singh et al. 2006) and it has been proposed that IFN- $\gamma$ kills the pathogen through autophagy. CD40 stimulation of $T$. gondii-infected macrophages causes recruitment of the highly specific autophagy marker Atg8 (LC3) around the parasitophorous vacuole (Andrade et al. 2006). This phenomenon precedes recruitment of LAMP-1 around the parasitophorous vacuole suggesting that autophagy may be responsible for vacuole-lysosomal fusion (Andrade et al. 2006). Indeed, knock-down of the autophagy molecule-Atg6 (Beclin 1) revealed that autophagy mediates fusion of the parasitophorous vacuole with late endosomes-lysosomes and killing of T. gondii in CD40-activated macrophage (Andrade et al. 2006). These studies established that autophagy can be activated by adaptive immunity to kill a pathogen.

Recent studies revealed that CD40 signals through adapter proteins to trigger autophagy (Subauste et al. 2007a). TNF Receptor Associated Factors (TRAF) are adapter proteins recruited to the intra-cytoplasmic tail of CD40 (Bishop et al. 2007). CD40 has two binding sites that directly recruit TRAF2 and TRAF3 and a binding site that directly recruits TRAF6 (Ishida et al. 1996, Pullen et al. 1998, Lu et al. 2003). The TRAF6 binding site plays a dual role in the autophagic killing of $T$. gondii: it enhances autocrine production of TNF- $\alpha$ (Mukundan et al. 2005) and TRAF6 signaling downstream of CD40 synergizes with TNF- $\alpha$ to activate autophagy (Subauste et al. 2007a). As a result, autophagosomes are recruited around the parasitophorous vacuole and this is followed by Rab7-dependent fusion with late endosomes-lysosomes and killing of T. gondii (Andrade 2005b, 2006) (Figure).

IFN- $\gamma$ also induces recruitment of autophagosomes around $T$. gondii (Ling et al. 2006). However, this phenomenon follows disruption of the parasitophorous vacuole membrane (Ling et al. 2006), a mechanism by which IFN- $\gamma$ has been reported to kill T. gondii (Martens et al. 2005). Therefore, autophagosome formation in IFN- $\gamma$-treated macrophages is unlikely to mediate anti-microbial activity against the parasite but rather is a response to removal of altered intracellular structures: disrupted parasitophorous membranes and dead tachyzoites. Importantly, studies in human and mouse macrophages demonstrated that pharmacological inhibition of lysosomal enzymes, vacuolar ATPase, PI3K (including the autophagy inhibitor 3-methyl adenine), knockdown of hVps34, expression of dominant negative Rab7, knockdown of Beclin 1 did not inhibit antimicrobial activity induced by IFN- $\gamma$ but ablated CD40induced toxoplasmacidal activity (Andrade et al. 2006). The different mechanisms used by CD40 and IFN- $\gamma$ to kill $T$. gondii may contribute to the cooperation observed between CD40 and IFN- $\gamma$ to promote control of the parasite (Andrade et al. 2003).

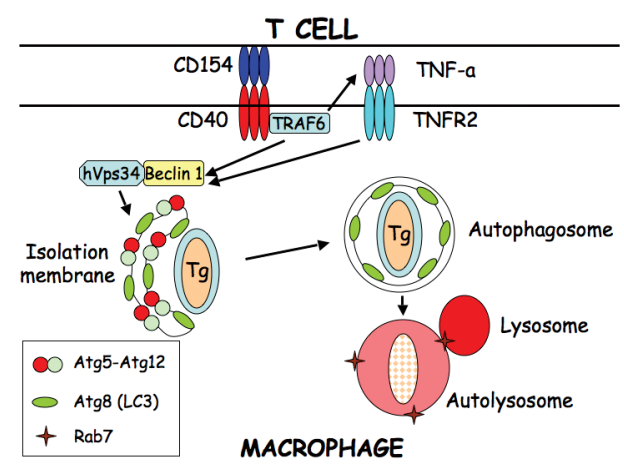

Model of autophagy-dependent killing of Toxoplasma gondii induced by CD40. T. gondii-specific CD4 ${ }^{+} \mathrm{T}$ cell acquires expression of CD154 after interaction with infected macrophages. CD40-CD154 binding results in recruitment of TNF Receptor Associated Factors 6 (TRAF6) to the intracytoplasmic tail of CD40 that in turn enhances TNF- $\alpha$ production. TRAF6 signals downstream of CD40 and TNF- $\alpha$ signaling synergize to trigger autophagy. Beclin 1 together with hVps34 promotes recruitment of autophagosome to the parasitophorous vacuole that contains the pathogen (Tg). Subsequent recruitment of Rab7 controls fusion with the lysosomes and killing of $T$. gondii.

\section{Potential relevance of CD40-induced autophagy in T. gondii infection}

Although autophagy appears to be involved in the clearance of the HSV-1 (Orvedahl et al. 2007), it has not been proven that autophagy mediates host protection in vivo. It is likely that autophagy is protective against T. gondii particularly in neural tissue. The role of macrophages/microglia as effector cells against $T$. gondii, the fact that mice deficient in the CD40 - CD154 pathway are susceptible to cerebral toxoplasmosis despite unimpaired upregulation of IFN- $\gamma$ together with the demonstration that CD40 induces autophagic killing of T. gondii independently of IFN- $\gamma / \mathrm{NOS} 2$ strongly suggest a paradigm where two arms of immunity: one dependent on IFN- $\gamma / \mathrm{NOS} 2$ and another dependent of CD40induced autophagy are required to control T. gondii in the brain. This paradigm can explain why IFN- $\gamma$ is insufficient for control of $T$. gondii in neural tissue (Yap et al. 1998, Reichmann et al. 2000).

Mouse models of $T$. gondii infection do not fully mimic immunity against $T$. gondii as it occurs in humans. Although IFN- $\gamma$ is clearly indispensable to control the parasite in mice, IFN- $\gamma$-independent mechanisms of resistance against $T$. gondii appear to be more effective in humans. Children with an autosomal dominant defect in IFN- $\gamma \mathrm{R} 1$ that causes a deletion in the STAT1 binding site do not develop disease when infected with $T$. gondii (Janssen et al. 2002). In marked contrast, STAT1 ${ }^{-/}$mice die within one week after infection with the parasite (Gavrielescu et al. 2004, Lieberman et al. 2004). The differences between the immune response in humans and mice also apply to the downstream effectors of IFN- $\gamma$. NOS2 in humans is more tightly regulated than in rodents and the production of nitric oxide appears to be weaker in humans than in mice (Kroncke et al. 1998). In addition, while mice have 23 IRG genes of which Irgml (LRG- 
47), $\operatorname{Irgm} 3$ (IGTP) and Irga6 (IIGP1) mediate anti-T. gondii activity in mouse cells (Collazo et al. 2001, 2002, Martens et al. 2005), IRG in humans have been reduced a truncated gene IRGM (syntenic with the mouse gene Irgml) and $I R G C$, both of which lack an IFN inducible element (Bekpen et al. 2005). CD40-induced autophagic killing of $T$. gondii may be an important contributor to control of $T$. gondii in humans because CD40 induces killing of $T$. gondii independently of IFN- $\gamma$, STAT1, NOS2 and IRG (Andrade et al. 2005a, 2006, Subauste \& Wessendarp 2006, Subauste et al. 2007a). Defects in the CD40 pathway are likely relevant to at least three groups of patients that develop cerebral and/or ocular toxoplasmosis: patients with X-linked Hyper IgM syndrome who lack functional CD154 (Subauste et al. 1999), newborns since neonatal $\mathrm{CD} 4^{+} \mathrm{T}$ cells exhibit impaired expression of CD154 (Durandy et al. 1995, Nonoyama et al. 1995, Julien et al. 2003, Han et al. 2004, Kaur et al. 2007) and neonatal dendritic cells have reduced levels of CD40 (Kaur et al. 2007). Impaired CD154 induction is particularly more pronounced in preterm babies (Kaur et al. 2007), a finding relevant to toxoplasmosis in newborns since this is an infection acquired prior to birth. The CD40-dependent pathway of host protection is also relevant to HIV-1 $1^{+}$patients because these individuals exhibit a defect in CD154 induction in their $\mathrm{CD} 4^{+} \mathrm{T}$ cells (Subauste et al. 2001, 2004, 2007b, Zhang et al. 2004).

The studies on CD40 uncovered a mechanism by which adaptive immunity utilizes autophagy to modify the fusogenic potential of pathogen-containing vacuoles leading to lysosomal dependent microbial killing. These results shed new light on the spectrum of mechanisms of resistance against $T$. gondii and are likely relevant to the pathogenesis of this disease as it occurs in humans. Not all CD $40^{+}$cells kill $T$. gondii after CD40 stimulation (Andrade et al. 2006). Future studies should identify the mechanisms activated by the parasite to avoid autophagy as well as determine whether manipulation of CD40 and autophagy signaling can enhance pathogen eradication.

\section{REFERENCES}

Andrade RM, Portillo JAC, Wessendarp M, Subauste CS 2005a. CD40 signaling in macrophages induces anti-microbial activity against an intracellular pathogen independently of IFN- $\gamma$ and reactive nitrogen intermediates. Infect Immun 73: 3115-3123.

Andrade RM, Wessendarp M, Gubbels MJ, Striepen B, Subauste CS 2006. CD40 induces macrophage anti-Toxoplasma gondii activity by triggering autophagy-dependent fusion of pathogen-containing vacuoles and lysosomes. J Clin Invest 116: 2366-2377.

Andrade RM, Wessendarp M, Portillo JAC, Yang JQ, Gomez FJ, Durbin JE, Bishop GA, Subauste CS 2005b. TRAF6 signaling downstream of CD40 primes macrophages to acquire anti-microbial activity in response to TNF- $\alpha$. J Immunol 175: 6014-6021.

Andrade RM, Wessendarp M, Subauste CS 2003. CD154 activates macrophage anti-microbial activity in the absence of IFN- $\gamma$ through a TNF- $\alpha$-dependent mechanism. J Immunol 171: 6750-6756.

Archbarou A, Mercereau-Puijalon O, Sadak A, Fortier B, Leriche MA, Camus D, Dubremetz JF 1991. Differential targeting of dense granule proteins in the parasitophorous vacuole of Toxoplasma gondii. Parasitology 103: 321-329.
Bekpen C, Hunn JP, Rohde C, Parvanova I, Guethlein L, Dunn DM, Glowalla E, Leptin M, Howard JC 2005. The interferon-inducible p47 (IRG) GTPases in vertebrates: loss of the cell autonomous resistance mechanism in the human lineage. Genome Biol 6: R92.

Birmingham CL, Smith AC, Bakowski MA, Yoshimori T, Brumell JH 2006. Autophagy controls Salmonella infection in response to damage to the Salmonella-containing vacuole. J Biol Chem 281: $11374-11383$

Bishop GA, Moore CR, Xie P, Stunz LL, Kraus ZJ 2007. TRAF proteins in CD40 signaling. Adv Exp Med Biol 597: 131-151.

Carruthers VB, Sibley D 1997. Sequential protein secretion from three distinct organelles of Toxoplasma gondii accompanies invasion of human fibroblasts. Eur J Cell Biol 73: 114-123.

Cesbron-Delauw MF 1994. Dense-granule organelles of Toxoplasma gondii: their role in the host-parasite relationship. Parasitol Today 10: 293-296.

Collazo CM, Yap G, Hieny S, Caspar P, Feng CG, Taylor GA, Sher A 2002. The function of gamma interferon-inducible GTPbinding protein IGTP in host resistance to Toxoplasma gondii is Stat1 dependent and requires expression in both hematopoietic and nonhematopoietic cellular compartments. Infect Immun 70: 6933-6939.

Collazo CM, Yap GS, Sempowski GD, Lusby KC, Tessarollo L, Vande Woude GF, Sher A, Taylor GA 2001. Inactivation of LRG-47 and IRG-47 reveals a family of interferon $\gamma$-inducible genes with essential, pathogen-specific roles in resisitance to infection. $J$ Exp Med 194: 181-187.

Coppens I, Dunn JD, Romano JD, Pypaert M, Zhang H, Boothroyd JC, Joiner KA 2006. Toxoplasma gondii sequesters lysosomes from mammalian hosts in the vacuolar space. Cell 125: 261-274.

Deckert M, Sedgwick JD, Fischer E, Schluter D 2006. Regulation of microglial cell responses in murine Toxoplasma encephalitis by CD200/CD200 receptor interaction. Acta Neuropathol 111: 548-558.

Deckert-Schluter M, Bluethmann H, Rang A, Hof H, Schluter D 1998. Crucial role of TNF receptor type 1 (p55), but not of TNF receptor type 2 (p75), in murine toxoplasmosis. J Immunol 160: 3427-3436.

Dunn WAJ 1994. Autophagy and related mechanisms of lysosomemediated protein degradation. Trends Cell Biol 110: 1923-1933.

Durandy A, de Saint Basile G, Lisowska-Grospierre B, Gauchat JF, Forveille M, Kroczek RA, Bonnefoy JY, Fischer A 1995. Undetectable CD40 ligand expression on T cells and low B cell responses to CD40 binding agonists in human newborns. J Immunol 154: 1560-1568.

Gavrielescu LC, Butcher BA, del Rio L, Taylor GA, Denkers EY 2004. STAT1 is essential for antimicrobial effector function but dispensable for gamma interferon production during Toxoplasma gondii infection. Infect Immun 72: 1257-1264.

Gazzinelli RT, Brezin A, Li Q, Nussenblatt RB, Chan CC 1994. Toxoplasma gondii: acquired ocular toxoplasmosis in the murine model, protective role of TNF- $\alpha$ and IFN- $\gamma$. Exp Parasitol 78: 217-229.

Gazzinelli RT, Eltoum I, Wynn TA, Sher A 1993. Acute cerebral toxoplasmosis is induced by in vivo neutralization of TNF- $\alpha$ and correlates with the down-regulated expression of inducible nitric oxide synthase and other markers of macrophage activation. J Immunol 151: 3672-3681.

Gazzinelli RT, Hakim FT, Hieny S, Shearer GM, Sher A 1991. Synergistic role of $\mathrm{CD}^{+}$and $\mathrm{CD}^{+} \mathrm{T}$ lymphocytes in IFN- $\gamma$ production and protective immunity induced by an attenuated Toxoplasma gondii vaccine. J Immunol 146: 286-292. 
Gutierrez MG, Master SS, Singh SB, Taylor GA, Colombo MC, Deretic V 2004. Autophagy is defense mechanism inhibiting BCG and Mycobacterium tuberculosis survival in infected macrophages. Cell 119: 753-766.

Hakansson S, Charron AJ, Sibley LD 2001. Toxoplasma evacuoles: a two-step process of secretion and fusion forms the parasitophorous vacuole. EMBO J 20: 3132-3144.

Han P, McDonald T, Hodge G 2004. Potential immaturity of the T-cell and antigen-presenting cell interaction in cord blood with particular emphasis on the CD40-CD40 ligand costimulatory pathway. Immunology 113: 26-34.

Hayashi S, Chan CC, Gazzinelli RT, Pham NTH, Cheung MK, Roberge FG 1996a. Protective role of nitric oxide in ocular toxoplasmosis. Br J Ophthalmol 80: 644-648.

Hayashi S, Chan CC, Gazzinelli R, Roberge FG 1996b. Contribution of nitric oxide to the host parasite equilibrium in toxoplasmosis. J Immunol 156: 1476-1481.

Ishida TK, Mizushima SI, Azuma S, Kobayashi N, Tojo T, Suzuki K, Aizawa S, Watanabe T, Mosialos G, Kieff E 1996. Identification of TRAF6, a novel tumor necrosis factor receptor-associated factor protein that mediates signaling from an amino-terminal domain of the CD40 cytoplasmic region. J Biol Chem 271: 28745-28748.

Janssen R, van Wengen A, Verhard E, de Boer T, Zomerdijk T, Ottenhoff THM, van Dissel JT 2002. Divergent role for TNF- $\alpha$ in IFN- $\gamma$-induced killing of Toxoplasma gondii and Salmonella typhimurium contributes to selective susceptibility of patients with partial IFN- $\gamma$ receptor 1 deficiency. J Immunol 169: 3900-3907.

Joiner KA, Fuhrman SA, Mietinnen H, Kasper LH, Mellman I 1990. Toxoplasma gondii: fusion competence of parasitophorous vacuoles in Fc receptor transfected fibroblasts. Science 249: 641-646.

Joiner KA, Roos DS 2002. Secretory traffic in the eukaryotic parasite Toxoplasma gondii: less is more. J Cell Biol 157: 557-563.

Julien P, Cron RQ, Dabbagh K, Cleary A, Chen L, Tran P, StepickBiek P, Lewis DB 2003. Decreased CD154 expression by neonatal $\mathrm{CD} 4^{+} \mathrm{T}$ cells is due to limitations in both proximal and distal events of T cell activation. Int Immunol 15: 1461-1472.

Kaur K, Chowdhury S, Greenspan NS, Schreiber JR 2007. Decreased expression of tumor necrosis factor family receptors involved in humoral immune responses in preterm neonates. Blood 110: 2948-2954.

Kihara A, Kabeya Y, Ohsumi Y, Yoshimori T 2001. Beclin-phosphatidylinositol 3-kinase complex functions at the trans-Golgi network. EMBO J 21: 330-335.

Kroncke KD, Fehsel K, Kolb-Bachofen V 1998. Inducible nitric oxide synthase in human disease. Clin Exp Immunol 113: 147-156.

Leiva LE, Junprasert J, Hollenbaugh D, Sorensen RU 1998. Central nervous system toxoplasmosis with an increased proportion of circulating $\gamma \delta \mathrm{T}$ cells in a patient with hyper IgM syndrome. J Clin Immunol 18: 283-290.

Levine B, Klionsky DJ 2004. Development by self-digestion: molecular mechanisms and biological functions of autophagy. Dev Cell 6: 463-477.

Lieberman LA, Banica M, Reiner SL, Hunter CA 2004. STAT1 plays a critical role in the regulation of antimicrobial effector mechanisms, but not in the development of Th1-type responses during toxoplasmosis. J Immunol 172: 457-463.

Ling YM, Shaw MH, Ayala C, Coppens I, Taylor GA, Ferguson DJP, Yap G 2006. Vacuolar and plasma membrane stripping and autophagic elimination of Toxoplasma gondii in primed effector macrophages. J Exp Med 203: 2063-2071.
Lu LF, Cook WJ, Lin LL, Noelle RJ 2003. CD40 signaling through a newly identified tumor necrosis factor receptor-associated factor 2 (TRAF2) binding site. J Biol Chem 278: 45414-45418.

Martens S, Parvanova I, Zerrahn J, Griffiths G, Schell G, Reichmann G, Howard JC 2005. Disruption of Toxoplasma gondii parasitophorous vacuoles by the mouse p47-resistance GTPases. PLoS Pathogens 1: 187-201.

Melendez A, Talloczy Z, Seaman M, Eskelinen EL, Hall DH, Levine B 2003. Autophagy genes are essential for dauer development and life-span extension in C. elegans. Science 301: 1387-1391.

Mizushima N, Ohsumi Y, Yoshimori T 2002. Autophagosome formation in mammalian cells. Cell Struct Funct 27: 421-429.

Mordue DG, Sibley LD 1997. Intracellular fate of vacuoles containing Toxoplasma gondii is determined at the time of formation and depends on the mechanisms of entry. J Immunol 159: 4452-4459.

Mukundan L, Bishop GA, Head KZ, Zhang L, Wahl L, Suttles J 2005. TNF receptor-associated factor 6 is an essential mediator of CD40-activated proinflammatory pathways in monocytes and macrophages. J Immunol 174: 1081-1090.

Nakagawa I, Amano A, Mizushima N, Yamamoto A, Yamaguchi H, Kamimoto T, Nara A, Funao J, Nakata M, Tsuda K, 2004. Autophagy defends cells against invading Group A Streptococcus. Science 306: 1037-1040.

Nonoyama S, Penix LA, Edwards CP, Lewis D, Ito S, Aruffo A, Wilson CB, Ochs HD 1995. Diminished expression of CD40 ligand by activated neonatal T cells. J Clin Invest 95: 66-75.

Ogawa M, Yoshimori T, Suzuki T, Sagara H, Mizushima N, Sasakawa C 2004. Escape of intracellular Shigella from autophagy. Science 307: 727-731.

Ohsumi Y 2001. Molecular dissection of autophagy: two ubiquitinlike systems. Nat Rev Mol Cell Biol 2: 211-216.

Orvedahl A, Alexander D, Talloczy Z, Sun Q, Wei Y, Zhang W, Burns D, Leib DA, Levine B 2007. HSV-1 ICP34.5 confers neurovirulence by targeting the Beclin 1 autophagy protein. Cell Host \& Microbe 1: 23-35.

Pullen SS, Miller HG, Everdeen DS, Dang TT, Crute JJ, Kehry MR 1998. CD40-tumor necrosis factor receptor-associated factor (TRAF) interactions: regulation of CD40 signaling through multiple TRAF binding sites and TRAF hetero-oligomerization. Biochemistry 37: 11836-11845.

Qu X, Yu J, Bhagat G, Furuya N, Hibshoosh H, Troxel A, Rosen J, Eskelinen EL, Mizushima N, Ohsumi Y 2003. Promotion of tumorigenesis by heterozygous disruption of the beclin 1 autophagy gene. J Clin Invest 112: 1809-1820.

Ravikumar B, Duden R, Rubinsztein DC 2002. Aggregate-prone proteins with polyglutamine and polyalanine expansions are degraded by autophagy. Hum Mol Genet 11: 1107-1117.

Reichmann G, Walker W, Villegas EN, Craig L, Cai G, Alexander J, Hunter CA 2000. The CD40/CD40 ligand interaction is required for resistance to toxoplasmic encephalitis. Infect Immun 68: 1312-1318.

Rich KA, Burkett C, Webster P 2003. Cytoplasmic bacteria can be targets for autophagy. Cell Microbiol 5: 455-468.

Robben PM, LaRegina M, Kuziel WA, Sibley LD 2005. Recruitment of $\mathrm{Gr}-\mathrm{1}^{+}$monocytes is essential for control of acute toxoplasmosis. J Exp Med 201: 1761-1769.

Roberts F, Roberts CW, Ferguson DJP, McLeod R 2000. Inhibition of nitric oxide production exacerbates chronic ocular toxoplasmosis. Parasite Immunol 22: 1-5. 
Scharton-Kersten T, Yap G, Magram J, Sher A 1997. Inducible nitric oxide is essential for host control of persistent but not acute infection with the intracellular pathogen Toxoplasma gondii. J Exp Med 185: 1261-1273.

Schluter D, Lohler J, Deckert M, Hof H, Schwendemann G 1991. Toxoplasma encephalitis of immunocomptetent and nude mice: immunohistochemical characterisation of Toxoplasma antigen, infiltrates and major histocompatibility complex gene products. J Neuroimmunol 31: 185-198.

Singh SB, Davis AS, Taylor GA, Deretic V 2006. Human IRGM induces autophagy to eliminate intracellular mycobacteria. Science 313: 1438-1441.

Subauste CS, Andrade RM, Wessendarp M 2007a. CD40-TRAF6 and autophagy-dependent anti-microbial activity in macrophages. Autophagy 3: 245-248.

Subauste CS, Subauste A, Wessendarp M 2007b. Role of CD40dependent down-regulation of CD154 in impaired induction of CD154 in $\mathrm{CD}^{+}{ }^{+} \mathrm{T}$ cells from HIV-1-infected patients. J Immunol 178: $1645-1653$.

Subauste CS, Wessendarp M 2000. Human dendritic cells discriminate between viable and killed Toxoplasma gondii tachyzoites: Dendritic cell activation after infection with viable parasites results in CD28 and CD40 Ligand signaling that controls IL-12-dependent and -independent T cell production of IFN- $\gamma$. J Immunol 165: 1498-1505.

Subauste CS, Wessendarp M 2006. CD40 restrains the in vivo growth of Toxoplasma gondii independently of gamma interferon. Infect Immun 74: 1573-1579.

Subauste CS, Wessendarp M, Portillo JAC, Andrade RM, Hinds LM, Gomez FJ, Smulian AG, Grubbs PA, Haglund LA 2004. Patho- gen-specific induction of CD154 is impaired in CD4 ${ }^{+} \mathrm{T}$ cells from HIV-infected individuals. J Infect Dis 189: 61-70.

Subauste CS, Wessendarp M, Smulian AG, Frame PT 2001. Role of CD40 ligand signaling in defective type-1 cytokine response in HIV infection. J Infect Dis 183: 1722-1731.

Subauste CS, Wessendarp M, Sorensen RU, Leiva L 1999. CD40 CD40 ligand interaction is central to cell-mediated immunity against Toxoplasma gondii: patients with hyper IgM syndrome have a defective type-1 immune response which can be restored by soluble CD40L trimer. J Immunol 162: 6690-6700.

Suzuki Y, Conley FK, Remington JS 1989. Importance of endogenous IFN- $\gamma$ for prevention of toxoplasmic encephalitis in mice. $J$ Immunol 143: 2045-2050.

Suzuki Y, Orellana MA, Schreiber RD, Remington JS 1988. Interferon- $\gamma$ : the major mediator of resistance against Toxoplasma gondii. Science 240: 516-518.

Talloczy Z, Jiang W, Virgin HW, Leib DA, Scheuner D, Kaufman RJ, Eskelinen EL, Levine B 2002. Regulation of starvation and virus-induced autophagy by the eIF $2 \alpha$ signaling pathway. Proc Natl Acad Sci USA 99: 190-195.

van Kooten C, Banchereau J 2000. CD40-CD40 ligand. J Leuk Biol 67: 2-17.

Yap GS, Scharton-Kersten T, Charest H, Sher A 1998. Decreased resistance of TNF receptor p55- and p75-deficient mice to chronic toxoplasmosis despite normal activation of inducible nitric oxide synthase in vivo. J Immunol 160: 1340-1345.

Zhang R, Fichtenbaum CJ, Hildeman DA, Lifson JD, Chougnet C 2004. CD40 ligand dysregulation in HIV: HIV glycoprotein 120 inhibits signaling cascades upstream of CD40 ligand transcription. J Immunol 172: 2678-2686. 